\title{
Experiencia clínica pediátrica en endocarditis infecciosa por Candida spp
}

\author{
Pedro Antonio Martínez ${ }^{1,2}$, Martín Guerrero ${ }^{1,2}$, José Écil Santos ${ }^{1,2}$, \\ María Santos Hernández³ y Mónica Cecilia Mercado ${ }^{1,2}$
}

\section{Pediatric clinical experience in infectious endocarditis due to Candida spp}

Background: Treatment and outcome of Candida spp infectious endocarditis in children it most be based on treatment guidelines, however there are some controversies. Aim: To describe our experience on treatment of pediatric candidal infective endocarditis. Methods: Analytic prospective study, from January 2006 to December 2017. Parametric analysis for quantitative variable. Proportions were compared by $\chi^{2}$ and exact Fisher Test CI 95\%. Mortality rate. Results: 25 episodes of Candida spp infective endocarditis were treated with standard antifungal drugs. Mortality rate was higher on patients submited to endocardic vegetation resection $(66.7 \%) \mathrm{RR}=3.16,\left(\chi^{2}\right.$ $\mathrm{p}=0.029)$, children with lymphohemophagocytic syndrome (LHFS) $(50 \%) \mathrm{RR}=1.18\left(\chi^{2}=\right.$ N.S. $)$, in multidrug resistant bacterial co infection $(57.14 \%), \mathrm{RR}=2,\left(\chi^{2}=\mathrm{NS}\right)$ also thrombotic endocarditis $(88.9 \%) \mathrm{RR}=4.74\left(\chi^{2}\right.$ $\mathrm{p}=0.004)$. Conclusion: Multidrug resistant bacteria co infection with Candida sp IE, LHFS, and/or surgical treatment of endocardic vegetation, might be considered as bad prognostic factors.

Keywords: Infective endocarditis; Candida sp; lymphohemophagocytosis; Pseudomonas aeruginosa; Staphylococcus aureus; amphotericin B.

Palabras clave: Endocarditis infecciosa; Candida; linfo-hemofagocitosis; Pseudomonas aeruginosa; Staphylococcus aureus; anfotericina B.

\section{Introducción}

$\mathrm{E}$ ntre 1 y $10 \%$ de las endocarditis infecciosas (EI) asociadas a los cuidados de la salud son causadas por hongos, más de la mitad, por especies de Candida. En pacientes críticamente enfermos la mortalidad alcanza a $50 \%{ }^{1} \mathrm{y}$, en particular en recién nacidos pre término, el promedio es de $30 \%$.

La EI por Candida albicans se ha asociado también a bacteriemias y a diarrea por Clostridium difficile ${ }^{2,3}$.

Mientras que el tratamiento con antifúngicos para EI por Candida spp está bien establecido, la resección quirúrgica de la(s) vegetació(es) podría otorgar un beneficio adicional, ante una falla terapéutica por la formación de biopelículas de Candida spp en catéteres, la pobre penetración de antifúngicos en la vegetación y al riesgo de embolismo a grandes vasos u órganos ${ }^{4}$. Un meta-análisis de 2015 reportó que, cuando se utilizaba la combinación de anfotericina B (anf-B) con otro antifúngico la mortalidad era menor que utilizando monoterapia; además, aunque se observó el deceso en $40 \%$ de los sometidos a resección quirúrgica, la mortalidad fue mayor entre aquellos niños que sólo recibieron tratamiento médico ${ }^{5}$.

Las guías de la Sociedad Americana para las Enfermedades Infecciosas (IDSA) de 2016, recomiendan que, bajo 3 meses de edad, se utilice anf-B deoxicolato, a dosis de $1 \mathrm{mg} / \mathrm{kg} /$ día por su buena penetración a sistema nervioso central. Anfotericina B de formulación lipídica en dosis de 3 a $5 \mathrm{mg} / \mathrm{kg} /$ día también es buena opción o equinocandinas en altas dosis, pero se recomiendan sólo como terapia de salvataje o en casos donde la toxicidad por AnB quiera ser evitada ${ }^{6}$.

El tratamiento quirúrgico también es objeto de controversia. Cuando la resección de la vegetación se lleva a cabo en la primera semana de tratamiento médico, parece disminuir la mortalidad al limitar el desarrollo de insuficiencia cardiaca y embolismo; sin embargo, en más de la mitad de los casos se realiza tardíamente o no se lleva a cabo, debido a las condiciones pre existentes de los pacientes, o a la posibilidad de empeoramiento de las mismas ${ }^{7}$.

Este estudio tiene como objetivo, describir nuestra experiencia en el tratamiento de EI por Candida en pacientes bajo 15 años de edad.

\section{Material y Métodos}

Estudio prospectivo, analítico, con muestras consecutivas, no aleatorias, de pacientes internados en la División de Pediatría del Hospital Civil de Guadalajara
Hospital Civil de Guadalajara "Fray Antonio Alcalde", México. 'Departamento de Infectología Pediátrica.

${ }^{2}$ Departamento de Cardiología Pediátrica.

${ }^{3}$ Universidad de Guadalajara, México Centro Universitario Ciencias de la Salud.

Se declara la ausencia de conflicto de interés.

No hubo financiamiento para su elaboración.

Recibido: 20 de junio de 2017 Aceptado: 25 de julio de 2018

Correspondencia a:

Mónica Cecilia Mercado Uribe monicauribe_99@yahoo.com.mx 
"Fray Antonio Alcalde" (HCG FAA) desde enero de 2006 a diciembre de 2017. Incluimos episodios de EI con aislamiento de Candida sp en sangre y asociados a otras bacterias de origen en los cuidados de la salud, obtenidos de registros clínicos de pacientes con edades entre un mes y 14 años y 11 meses de edad.

Excluimos del análisis los episodios de EI de etiología puramente bacteriana. Los pacientes cumplieron los criterios de Duke modificados para diagnóstico de $\mathrm{EI}^{8}$, así como ecocardiograma transtorácico (ETT) con evidencia de vegetación endocárdica, realizado e interpretado por dos cardiólogos pediatras con entrenamiento certificado en ecocardiografía.

Los criterios clínicos que se adhieren a la recomendación de manejo quirúrgico de la vegetación endocárdica, incluyeron:

- Hemocultivo con crecimiento para especies de Candida sp asociada a EI.

- Etiología bacteriana multi-resistente (Pseudomonas aeruginosa, Staphylococcus aureus resistente a meticilina (SARM), otros).

- Vegetación sésil con riesgo de desprendimiento y embolización a otros órganos.

- Tamaño superior a $10 \mathrm{~mm}$ persistente a pesar de tratamiento médico.

- Localización en la vena cava o válvula tricuspídea ${ }^{4}$.

Cada aislado de Candida sp fue re-sembrado en cromo agar. La susceptibilidad in vitro a agentes anti fúngicos fue evaluada por medio del sistema VITEK $2 \mathrm{~S}$. Durham California, basados en el CLSI con puntos de corte para fluconazol: Susceptible (S): $8 \mu \mathrm{g} / \mathrm{ml})$, Susceptible Dosis Dependiente (SDD): 16-32 $\mu \mathrm{g} / \mathrm{ml}$, Resistente (R): $64 \mu \mathrm{g} /$ $\mathrm{ml}$, voriconazol (S): $1 \mu \mathrm{g} / \mathrm{ml}$, (SDD): $2 \mathrm{mg}$ l, (R): $4 \mu \mathrm{g} /$ $\mathrm{ml}$; anf-B, sin puntos de corte interpretativos, los aislados de Candida sp se consideraron susceptibles cuando la concentración inhibitoria mínima (CIM) fue $1 \mu \mathrm{g} / \mathrm{ml}$. Caspofungina y micafungina (CIM) $<2 \mu \mathrm{g} / \mathrm{ml}>2 \mu \mathrm{g} / \mathrm{ml}$ (R) ${ }^{9}$. No todas las cepas de Candida sp fueron sometidas a análisis de susceptibilidad in vitro.

La elección del tratamiento con anB de complejo lipídico fue con base en las guías de manejo de EI fúngica en niños; en nuestro país no se encuentra disponible 5-flucitocina, por lo que en algunos casos fue combinada con azoles o caspofungina. Se utilizó únicamente caspofungina cuando el paciente cursó con insuficiencia renal o falla multiorgánica. Voriconazol fue combinado con anB, ante la falla terapéutica clínica, la imposibilidad de retirar el catéter venoso central, y/o de practicar la resección quirúrgica, y antecedente de haber empleado previamente caspofungina.

\section{Análisis estadístico}

Los datos fueron registrados en una base Excel 2013, y posteriormente analizados por el programa SPSS 23.0 El análisis de las variables cualitativas se realizó comparando proporciones y razones por medio de $\chi^{2}$ y prueba exacta de Fisher con IC al 95\%. Las variables cuantitativas por medio de análisis de frecuencias, medias, desviación estándar e intercuartiles. Determinamos tasa de mortalidad para EI por Candida sp.

\section{Resulltados}

Analizamos 25 de 89 casos que cumplieron criterios de Duke para EI, en cuyo hemocultivo se aislara una especie de Candida spp.

\section{Características clínicas y demográficas}

La serie clínica tuvo predominio del sexo masculino (64\%). Resaltan como factores de importancia para EI, la edad en promedio 12 meses, con antecedentes de prematurez y genopatía en la mitad de los casos.

La sospecha clínica de EI fue sugerida cuando la fiebre, leucocitosis, plaquetopenia, anemia y el aislamiento de Candida spp fueron persistentes y se llegó a reconocer la EI con seguimiento eco cardiográfico cada tres a siete días (Tabla 1).

Hubo uso previo de antimicrobianos en la totalidad de los pacientes, frecuentemente en respuesta a co infección por agentes multi-resistentes, $P$. aeruginosas, S.aureus, Klebsiella pneumoniae y Acinetobacter baumannii, entre otros.

Todos los pacientes tuvieron candidemia asociada a catéter venoso central (CVC) y de una a tres vegetaciones endocárdicas, con predominio de localización en el atrio izquierdo, aorta y vena cava superior; la mayoría de ellas con más de $10 \mathrm{~mm}$ de longitud, sésiles y en su seguimiento ecocardiográfico desaparecieron en promedio dos semanas después de iniciado el tratamiento médico, al mismo tiempo que ocurrió el aclaramiento del hemocultivo.

Durante los primeros años, predominó Candida albicans en los episodios de EI, pero a partir de 2016 se incorporaron otras especies, entre ellas C. krusei, famata y guilliermondii, con un comportamiento in vivo mucho más agresivo (Gráfico 1). Encontramos sensibilidad a AnB en 100\% de las cepas de Candida (n: 16), con CIM promedio de $0,38 \mu \mathrm{g} / \mathrm{mL}$. Para caspofungina (n: 14) la CIM fue $0,48 \mathrm{mg} / \mathrm{mL}$. Ninguna cepa demostró resistencia a AnB (Tabla 2).

\section{Intervenciones terapéuticas}

La evolución clínica compleja de los pacientes indujo a utilizar variados antimicrobianos y ajustes terapéuticos con frecuencia. En la mayoría de los casos, se indicó antimicrobianos $\beta$-lactámicos, acompañados de aminoglucósidos en un primer esquema, seguido del empleo 


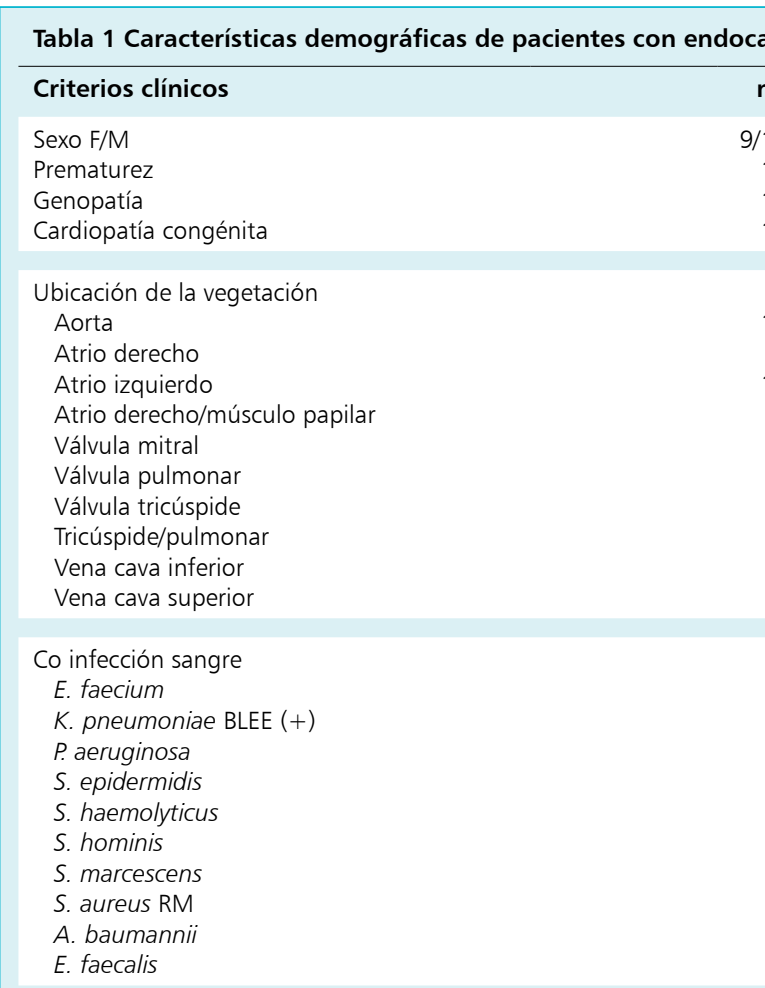

\begin{tabular}{|c|c|c|c|c|c|c|c|}
\hline \multirow[t]{2}{*}{ Características } & \multirow[t]{2}{*}{ Min } & \multirow[t]{2}{*}{ Max } & \multirow[t]{2}{*}{ Media } & \multirow[t]{2}{*}{ DS } & \multicolumn{3}{|c|}{ Intercuartiles } \\
\hline & & & & & 25 & 50 & 75 \\
\hline \multicolumn{8}{|l|}{ Factores de riesgo } \\
\hline Antimicrobianos previos & 2 & 15 & 5,1 & 3,3 & 3 & 5 & 6 \\
\hline Días CVC & 2 & 70 & 38 & 25,1 & 16 & 30 & 60 \\
\hline Días NPT & 0 & 125 & 32,7 & 29,6 & 16 & 30 & 45 \\
\hline Edad (meses) & 1 & 168 & 12,5 & 34,5 & 2 & 2 & 5 \\
\hline Número vegetaciones & 1 & 3 & 1,2 & 0,523 & 1 & 1 & 1 \\
\hline Largo vegetación 1 (mm) & 2 & 27 & 11,5 & 7,6 & 5 & 11 & 27 \\
\hline Ancho vegetación 1 (mm) & 1 & 20 & 7,1 & 4,5 & 5 & 6 & 8 \\
\hline Largo vegetación $2 \quad(\mathrm{~mm})$ & 0,0 & 6 & 1,7 & 2,4 & 0,1 & 0,5 & 3,8 \\
\hline Ancho vegetación $2(\mathrm{~mm})$ & 0,0 & 3 & 0,5 & 1,3 & 0 & 0,5 & 2,2 \\
\hline Largo vegetación $3 \quad(\mathrm{~mm})$ & 0,0 & 2 & 0,25 & 1 & 0 & 0 & 1,5 \\
\hline Ancho vegetación 3 (mm) & 0 & 1 & 0,25 & 0,5 & 0 & 0 & 0,7 \\
\hline Leucocitos $\mu / \mathrm{L}$ & 5.000 & 24.700 & 13.220 & 6.152 & 7.767 & 11.320 & 8.150 \\
\hline Neutrófilos $\mu / L$ & 1.030 & 19.700 & 6.349 & 4.836 & 2.830 & 4.910 & 10.900 \\
\hline Hemoglobina (gr/L) & 7 & 15 & 10,6 & 2,0 & 8,8 & 10,6 & 12,5 \\
\hline Plaquetas $\mu / \mathrm{L}$ & 167.0 & 713,7 & 206,2 & 171,4 & 580,7 & 665,0 & 996,2 \\
\hline Bilirrubina (mg/L) & 0 & 18 & 4,1 & 5,3 & 0,5 & 0,9 & 7,5 \\
\hline Albúmina $(\mathrm{g} / \mathrm{L})$ & 2 & 4 & 2,8 & 0,72 & 2,2 & 2,8 & 3,2 \\
\hline Colesterol (mg/L) & 38 & 359 & 144,4 & 95 & 82 & 128 & 147 \\
\hline Triglicéridos (mg/L) & 112 & 764 & 268 & 204 & 123 & 218 & 357 \\
\hline Dímero D $(U)$ & 104 & 5.000 & 1.964 & 1.766 & 557 & 1.423 & 3.642 \\
\hline Fibrinógeno $(U)$ & 96 & 899 & 352 & 227 & 180 & 287 & 493 \\
\hline Ferritina $(U)$ & 143 & 3.870 & 1.430 & 1.102 & 725 & 1.411 & 1.537 \\
\hline Días hasta ceder la fiebre & 0 & 30 & 11,5 & 8,3 & 5 & 10 & 15 \\
\hline Días hasta negativización de hemocultivo & 3 & 60 & 18,2 & 15 & 6 & 15 & 29 \\
\hline Días hasta desaparición de la vegetación & 7 & 60 & 25,4 & 14,21 & 15 & 21 & 31 \\
\hline
\end{tabular}


Grafico 1. Frecuencia de especies de Candida en hemocultivos de niños con endocarditis infecciosa entre enero de 2006 y diciembre de 2017 en el HCG FAA.

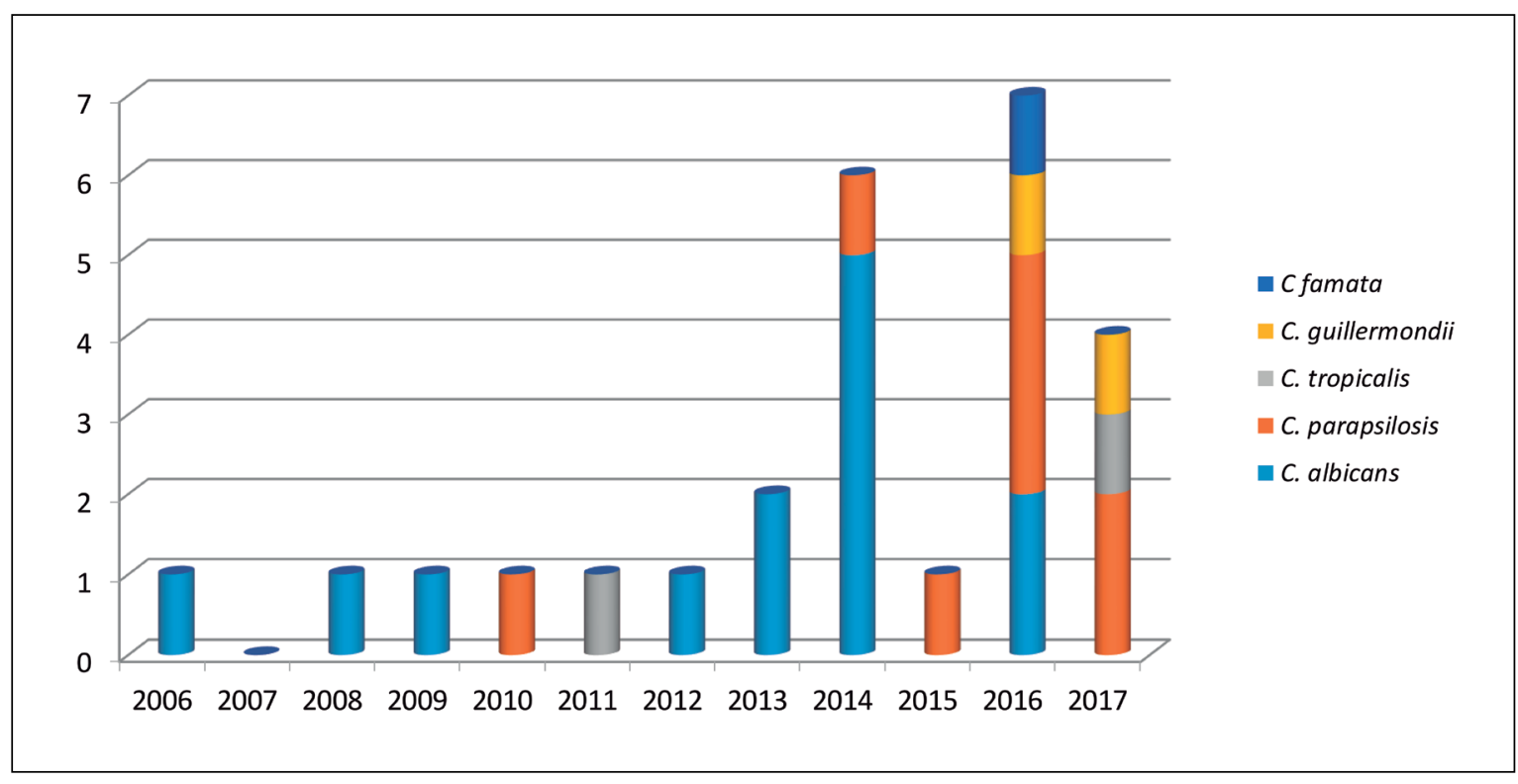

Tabla 2. Susceptibilidad a antifúngicos para especies de Candida aisladas de hemocultivos de pacientes con endocarditis infecciosa

\begin{tabular}{|c|c|c|c|c|c|c|}
\hline Caso & Candida & $\begin{array}{c}\text { Anf-B } \\
\mathrm{S}<1 \mathrm{mg} / \mathrm{ml}\end{array}$ & $\begin{array}{l}\text { Caspo (S) } \\
<2 \mathrm{mg} / \mathrm{ml}\end{array}$ & $\begin{array}{l}\text { Fluco (S) } \\
8 \mathrm{mg} / \mathrm{ml}\end{array}$ & $\begin{array}{l}\text { Vori (S) } \\
1 \mathrm{mg} / \mathrm{ml}\end{array}$ & $\begin{array}{c}\text { Mica (S) } \\
<2 \mathrm{mg} / \mathrm{m}\end{array}$ \\
\hline 1 & albicans & 0,5 & & & & \\
\hline 2 & parapsilosis & 0,25 & & & & \\
\hline 3 & albicans & 0,06 & 0,06 & & & \\
\hline 4 & albicans & 0,5 & 0,6 & & & \\
\hline 5 & tropicalis & 0,5 & 0,25 & & & \\
\hline 6 & parapsilosis & 0,5 & 0,2 & & & \\
\hline 7 & parapsilosis & 0,5 & 0,2 & & & \\
\hline 8 & parapsilosis & 0,5 & 0,2 & & & \\
\hline 9 & parapsilosis & 0,5 & 0,2 & & & \\
\hline 11 & guilliermondii & 0,5 & 1 & 0.2 & 0,12 & 2 \\
\hline 12 & albicans & 0,5 & 1 & 2 & 0,12 & \\
\hline 13 & tropicalis & 0,25 & 0,25 & 1 & 0,12 & 0.06 \\
\hline 14 & tropicalis & 0,25 & 0,25 & 1 & 0,12 & \\
\hline 15 & parapsilosis & 0,25 & 0,5 & 1 & 0,12 & 0.5 \\
\hline 16 & parapsilosis & 0,5 & 1 & 1 & 0,12 & 0.5 \\
\hline 17 & guilliermondii & 0,5 & 1 & 2 & 0,12 & 0.5 \\
\hline
\end{tabular}

de carbapenémicos y/o vancomicina; en algunos casos se utilizó esquemas repetidos, a consecuencia de nuevas bacteriemias, a través de CVC, lo que representó un promedio 31 días previos al diagnóstico de EI.

Como se recomienda en las guías de manejo para EI por Candida sp, utilizamos AnB en 16 casos sola o combinada (64\%), reservando el uso de caspofungina para los pacientes con falla renal.

El retiro del catéter se llevó a cabo en 13 pacientes $(52 \%)$ dentro de la siguiente semana del aislamiento de Candida sp en sangre. Los 12 pacientes restantes, en quienes no se retiró el dispositivo, cursaron con gravedad, en ocasiones asociada a la presencia de coagulación intravascular diseminada (CID) o síndrome linfo-hemofagocítico (SLHF); este segundo estuvo presente en seis pacientes (24\%) y el RR para mortalidad fue de 1,8 (IC al $95 \%$ $0,46-3,10)$. Otros factores considerados para no retirar el CVC fueron incapacidad para canalizar otra vía endovenosa, adherencia del catéter a la vegetación endocárdica con riesgo de desprendimiento y embolización a grandes vasos. La mortalidad global para los pacientes en quienes no se retiró el CVC fue de 50\% con $\mathrm{RR}=1,6$ (IC 95\% 0,63-4,16) Prueba exacta de Fisher NS (Tabla 3).

Todos los pacientes recibieron antifúngicos, seis de ellos recibieron además tratamiento quirúrgico (24\%), incluyendo a cuatro niños con vegetación adherida al CVC y portadores de SLHF. En estos casos se consideró de mayor beneficio el abordaje quirúrgico, una vez que se estabilizó al paciente con tratamiento dirigido para el SLHF y la CID. 


\begin{tabular}{|c|c|c|c|c|c|}
\hline Caso & Días previo & $\begin{array}{c}\text { Tratamiento } \\
\text { (semanas) }\end{array}$ & Retiro de CVC & Cirugía & Evolución \\
\hline 1 & 20 & Anf-B 2 & $\mathrm{Si}$ & No & Curación \\
\hline 2 & 30 & Caspo 4 & Si & No & Curación \\
\hline 3 & 15 & Anf-B Fluco 3 & No & No & Muerte tardía El trombótica \\
\hline 4 & 30 & Anf-B Caspo 4 & No & No & El trombótica \\
\hline 5 & 65 & Anf-B 5 & Si & No & Curación \\
\hline 6 & 60 & Caspo 3 & No & Semana 1 & Muerte en cirugía \\
\hline 7 & 18 & Caspo 4 & $\mathrm{Si}$ & Semana 4 & Curación \\
\hline 8 & 20 & Fluco 3 & Si & No & Curación \\
\hline 9 & 21 & Anf-B Fluco 4 & $\mathrm{Si}$ & Sem 2 & Curación \\
\hline 10 & 15 & Anf-B 4 & Si & No & Curación \\
\hline 11 & 15 & Anf-B 4 & No & No & Muerte tardía \\
\hline 12 & 21 & Caspo 5 & No & Semana 5 & Muerte tardía \\
\hline 13 & 17 & Anf-B 4 & $\mathrm{Si}$ & No & Curación \\
\hline 14 & 21 & Anf-B Caspo 5 & $\mathrm{Si}$ & No & Curación \\
\hline 15 & 14 & Caspo 4 & Si & No & El trombótica \\
\hline 16 & 30 & Caspo 4 & No & No & El trombótica \\
\hline 17 & 30 & Anf-B Fluco Caspo 9 & No & No & Curación \\
\hline 18 & 30 & Anf-B Vori 4 & $\mathrm{Si}$ & Semana 3 & Muerte en cirugía \\
\hline 19 & 15 & Caspo10 & $\mathrm{Si}$ & Semana 8 & Muerte tardía \\
\hline 20 & 30 & Anf-B 4 & No & No & Curación \\
\hline 21 & 15 & Caspo Fluco 2 & No & No & Curación \\
\hline 22 & 30 & Anf-B 3 & No & No & Curación \\
\hline 23 & 80 & Anf-B 4 & $\mathrm{Si}$ & No & Muerte \\
\hline 24 & 88 & Anf-B 5 & No & No & Curación \\
\hline 25 & 60 & Anf-B 5 & No & No & Curación \\
\hline
\end{tabular}

CVC: catéter venoso central. Anf-B: anfotericina B. Fluco: fluconazol. Caspo caspofungina. Vori: voriconazol. El: endocarditis trombótica.

La decisión de someter a remoción quirúrgica una vegetación endocárdica dependió de la falla para negativizar los hemocultivos, la asociación con bacterias multiresistentes, el tamaño superior a $10 \mathrm{~mm}$ con condición asociada a embolismo de grandes vasos, entre las causas más importantes (Tabla 4).

La tasa de mortalidad entre los pacientes expuestos a cirugía para resección de vegetación endocárdica fúngica fue de $66,6 \%, \mathrm{RR}=3,16$ (IC al 95\% 1,12-8,95), $\chi^{2}=9,0$ $(\mathrm{p}=0,029)$, contrastando con la mortalidad entre no expuestos a cirugía: $21,5 \%$. No obstante, no encontramos diferencias significativas para mortalidad, entre el tiempo de espera de resección quirúrgica en las primeras dos semanas o tardíamente de cuatro a ocho semanas.

Si en los hemocultivos se aisló además, bacterias multi-resistentes, entre ellas $P$. aeruginosa, SARM o $K$. pneumoniae productora de $\beta$-lactamasas de espectro extendido ( $57,1 \%$ de los casos), el riesgo de mortalidad fue superior, $\mathrm{RR}=2\left(\chi^{2}=\mathrm{NS}\right)$.

\section{Discusión}

La frecuencia de EI por Candida spp se ha incrementado en las últimas dos décadas en nuestro hospital.

En la evaluación de neonatos con EI, encontramos un número inesperado de casos de SLHF, que puede tener como base origen genético, inmunodeficiencia e incluso infecciones como sepsis asociada a bacterias (Salmonella spp, Streptococcus pneumoniae, otras), infección por cito- 


\begin{tabular}{|c|c|c|c|}
\hline Caso & Tratamiento antifúngico & Criterios quirúrgicos & Evolución final \\
\hline 1 & Caspofungina & $\begin{array}{l}\text { Vegetación } 11 \text { mm sésil adherida a CVC, atrio derecho, cultivos persistente- } \\
\text { mente positivos, co infección con } A \text {. baumannii }\end{array}$ & Muerte transquirúrgica \\
\hline 2 & Caspofungina & $\begin{array}{l}\text { Vegetaciones de } 10 \text { y } 11 \text { mm, válvulas tricúspide y pulmonar. Embolia arterial } \\
\text { mayor, hemorragia cerebral, co infección con } P \text {. aeruginosa }\end{array}$ & Curación. Secuelas neurológicas \\
\hline 3 & Anf-B - fluconazol & $\begin{array}{l}\text { Vegetación } 14 \text { × } 13 \text { mm, atrio der, co infección SARM, infarto y hemorragia } \\
\text { cerebral, CID y SLHF tratados }\end{array}$ & Curación. Secuelas neurológicas \\
\hline 4 & Caspofungina & $\begin{array}{l}\text { Vegetación } 13 \mathrm{~mm} \text { en VCS, hemorragia cerebral, cultivos persistentemente } \\
\text { positivos, co infección } P \text {. aeruginosa y } E \text {. faecalis, CID tratada }\end{array}$ & $\begin{array}{l}\text { Insuficiencia cardiaca, secuelas neurológi- } \\
\text { cas. Muerte tardía }\end{array}$ \\
\hline 5 & Anf-B voriconazol & $\begin{array}{l}\text { Vegetación } 19 \text { × } 20 \text { mm, atrio der, embolia e infarto cerebral, CID, cultivos } \\
\text { persistentemente positivos, co infección } S \text {. hemolyticus }\end{array}$ & $\begin{array}{l}\text { Insuficiencia cardiaca. Muerte transqui- } \\
\text { rúrgica }\end{array}$ \\
\hline 6 & Caspofungina & $\begin{array}{l}\text { Vegetación } 11 \mathrm{~mm} \text {, atrio der, cultivos persistentemente positivos, co infección } \\
\text { E. faecium, dos especies de Candida, cardiopatía compleja, infarto cerebral }\end{array}$ & $\begin{array}{l}\text { Insuficiencia cardiaca, mediastinitis, secue- } \\
\text { las neurológicas. Muerte tardía }\end{array}$ \\
\hline Total & & & 4/6 defunciones \\
\hline
\end{tabular}

megalovirus y también hay reportes de casos asociados a Histoplasma capsulatum ${ }^{10,11}$. Corroboramos el diagnóstico de SLHF por fiebre persistente, hepato y esplenomegalia, anemia, trombocitopenia, hiper-trigliceridemia, hipofibrinogenemia, hiper-bilirrubinemia e hiper-transferritinemia y el hallazgo de linfo-hemofagocitosis en sangre periférica o médula ósea. El tratamiento de estos pacientes incluyó inmunoglobulina, concentrados de plasma y/o plaquetas, etopósido y ciclosporina ${ }^{12}$. Aunque en Asia es más frecuente, en México la prevalencia de este síndrome familiar se desconoce; se ha teorizado que podría estar asociado al uso de nutrición parenteral, en particular al papel tóxico de los lípidos ${ }^{13}$.

Algunos autores relacionan mayor gravedad y mortalidad entre pacientes neonatos con candidemia por cepas de C. parapsilosi ${ }^{14}$, nosotros no encontramos esta condición.

Aunque se ha encontrado mayor mortalidad entre los pacientes en quienes no se puede retirar el CVC, en nuestra experiencia no hubo diferencias significativas; sí, la evolución a EI trombótica, se relacionó a mayor riesgo de mortalidad ${ }^{14}$.

El ETT en niños es muy sensible para detectar vegetaciones por la buena ventana acústica y no tiene las desventajas de someter al paciente a intubación y ventilación mecánica bajo anestesia. Sin embargo, en los pacientes en quienes no se observa vegetación endocárdica en un primer estudio y con sospecha clínica o microbiológica de EI persistente, en nuestro centro protocolizamos el ETT repetitivo cada tres a cinco días ${ }^{4,15}$. El ecocardiograma trans-esofágico (ETE) 3D es ideal, especialmente para vegetaciones pequeñas; en los casos que no es concluyente este método, la tomografía con leucocitos marcados es de utilidad en particular para abscesos, fístulas y pseu- doaneurismas. En nuestro hospital carecemos de sonda pediátrica y de tomógrafo óptimo en número de cortes y personal capacitado para realizar angio TAC, que suele ser conveniente para válvulas protésicas más que para válvulas nativas.

Un aporte especial de este trabajo es el reporte de la asociación de EI por Candida sp a SLHF ${ }^{16}$.

En el futuro, será un reto evaluar el tratamiento con equinocandinas en población pediátrica, que podría tener un soporte mayor cuando se cuenten con estudios comparativos apropiados.

Limitantes en esta casuística son la falta de acceso a diagnóstico molecular que permitiría estudiar la virulencia de las cepas de Candida y su capacidad de producir biopelículas. Además, un tratamiento quirúrgico de EI tardío, en un número pequeño de pacientes, no permitió evaluar el impacto de la cirugía en evitar las complicaciones y el resultado final del tratamiento.

Agradecimientos. Al personal médico de las especialidades de cardio-cirugía y hematología pediátricas del HCGFAA, por el apoyo dispensado en la evaluación de los pacientes y a los químicos del laboratorio de microbiología por su apoyo en la identificación temprana y resguardo de las cepas bacterianas y fúngicas aisladas.

\section{Resumen}

Introducción: El tratamiento y evolución de endocarditis infecciosa por Candida spp en niños debe basarse en guías de manejo; sin embargo, aún existen controversias al respecto. Objetivo: Describir nuestra experiencia 
en el tratamiento de EI por Candida spp en pacientes pediátricos. Métodos: Estudio prospectivo, analítico, realizado entre enero de 2006 y diciembre 2017. Análisis paramétrico de variables cuantitativas; razones, proporciones, comparación por medio de $\chi^{2}$ y prueba exacta de Fisher con IC al $95 \%$ para variables no paramétricas. Tasa de mortalidad. Resultados: Veinticinco episodios de endocarditis por Candida spp recibieron tratamiento anti fúngico estándar. La mortalidad fue superior en pacientes sometidos a resección de la vegetación endocárdica $(66,7 \%)$ RR $3,16, \chi^{2} \mathrm{p}=0,029$, en niños con síndrome linfo-hemofagocítico SLHF (50\%), RR=1,18 ( $\left.\chi^{2} \mathrm{NS}\right)$, en co infección con bacterias multi-resistentes $(57,1 \%)$ $\mathrm{RR}=2,\left(\chi^{2} \mathrm{NS}\right)$ y en EI trombótica $(88,9 \%) \mathrm{RR}=4,74$ $\left(\chi^{2} \mathrm{p}=0,004\right)$. Conclusiones: Co-infección de EI por Candida sp con bacterias multi-resistentes, SLHF y/o manejo quirúrgico de la vegetación endocárdica, pueden considerarse factores de mal pronóstico.

\section{Referencias bibliográficas}

1.- Antinori S, Milazzo L, Sollima S, Galli M, Corbellino M. Candidemia and invasive candidiasis in adults: A narrative review. Eur J Intern Med 2016, http://dx.doi.org/10.1016/j. ejim.2016.06.029.

2.- Tahazzul M, Singh S N, Sharma A, Khan M W. Co-infection with bacterial and fungal endocarditis in neonate and successful medical treatment. Clin Epidemiol Glob Health 2014; 2: 47-9. https://doi.org/10.1016/j. cegh.2012.12.002.

3.- Benjamin D K, Stoll B J, Fanaroff A A, McDonald S A, Oh W, Higgings H D, et al. Neonatal candidiasis among extremely low birth weight infants: risk factors, mortality rates, and neuro developmental outcomes at 18 to 22 months. Pediatrics 2006; 117: 84-92. DOI: 10.1542/peds.2004-2292.

4.- Cahill T J, Prendergast B D. Current controversies in infective endocarditis. F1000 Faculty Rev 2015; 4: 1287- 94. doi: 10.12688/ f1000research.6949.1.

5.- Pana Z D, Dotis J, Iosifidis E, Roilides E. Fungal endocarditis in neonates. A review of seventy-one cases (1971-2013). Pediatr Infect Dis J 2015; 34: 803-8. doi: 10.1097/ INF.0000000000000735.
6.- Pappas P, Kauffman C A, Andes D R, Clancy C J, Marr K A, Ostrosky-Zeichner L, et al. Clinical practice guideline for the management of candidiasis: 2016 Update by the Infectious Diseases Society of America. Clin Infect Dis 2016; 62: e1-e50 doi: 10.1093/cid/civ933.

7.- Steinbach W J, Perfect J R, Cabell C H, Fowler V G, Corey G R, Li J S, et al. A meta-analysis of medical versus surgical therapy for Candida endocarditis. J Infect 2005; 51: 230-47 DOI: 10.1016/j.jinf.2004.10.016.

8.- Yanagawa B, Pettersson G B, Habib G, Ruel M, Saposnik G, Latter D A, et al. Surgical management of infective endocarditis complicated by embolic stroke. Practical recommendations for clinicians. Circulation 2016; 134: 1280-92 DOI: 10.1161/ CIRCULATIONAHA.116.024156.

9.- Durack D T. Duke criteria for infective endocarditis. MMWR Morb Mortal Wkly Rep 2013; 62: 26.

10.- Hawkshead J J, Van Dyke R B, Hassig S E, Webber L S, Begue R E. Species-based comparison of disease severity and risk factors for disseminated Candida infections in pediatric patients. Infect Drug Resist 2016; 9: 59-70. https://doi.org/10.2147/IDR.S102490.

11.- Wan Z, Duart A, Schnadig V G. Fatal reactive hemophagocytosis related to disseminated histoplasmosis with endocarditis: An unusual case diagnosed at autopsy. South Med J 2007; 100: 208-11.

12.- Naffaa M, Awad J, Oren I, Braun E, Lavi N. Group G streptococcal endocarditisassociated hemophagocytic síndrome. Int $\mathrm{J}$ Infect Dis 2013; 17: 1237- 9. doi: 10.1016/j. ijid.2013.05.004.

13.- Fisman D N. Hemophagocytic syndromes and infection. Emerg Infect Dis 2000; 6: 601-8. DOI: 10.3201/eid0606.000608.

14.- Cuenca-Estrella M, Alastruey-Izquierdo A, Gómez-López A, Monzón A. Estudios de sensibilidad en levaduras. Actualización y novedades. Enferm Infecc Microbiol Clin 2013; 31(Supl 1): 53-8.

15.- Humpl T, McCrindle B W, Smallhorn J F. The relative roles of transthoracic compared with transesophageal echocardiography in children with suspected infective endocarditis. JACC 2003; 41: 2068-71 doi:10.1016/S07351097(03)00419-4.

16.- Mercado Uribe M C, Navarro-Muñoz V, Maltez-Licona Z, Martínez Arce P A, Guerrero-Becerra M, Candelas-Delgado E, et al. Síndrome hemofagocítico asociado a endocarditis infecciosa en niños. Archivos de Ciencia 2015; 7: 47. http://dx.doi.org/10.4067/ S0370-41062005000400010. 